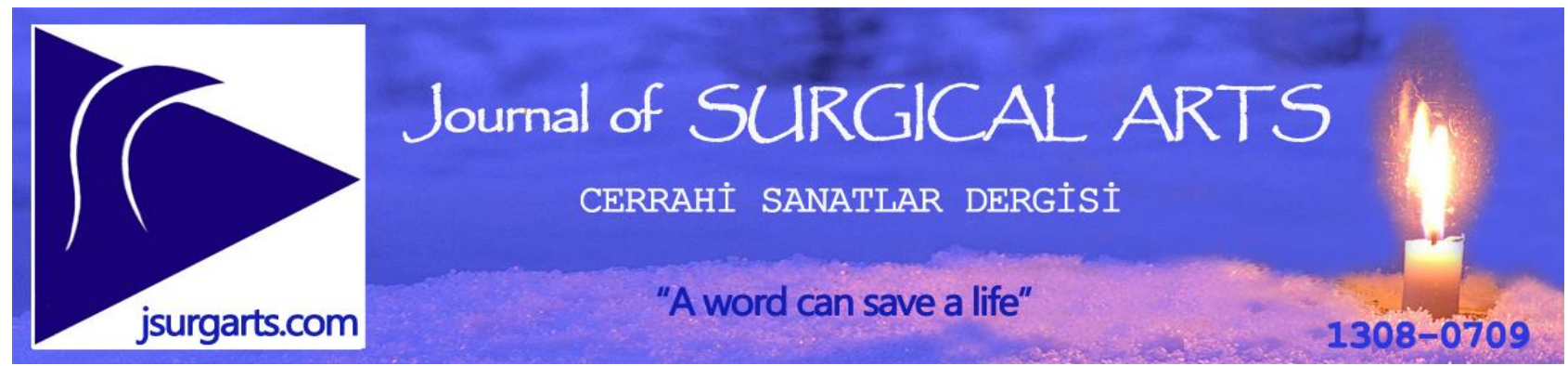

Case report

\title{
A case of solitary fibrous tumor incidentally detected during COVID-19 infection and treated with video-assisted thoracoscopic surgery
}

\section{COVID-19 enfeksiyonu sırasında tesadüfen saptanan ve video-yardımlı torakoskopik cerrahi ile tedavi edilen bir soliter fibröz tümör olgusu}

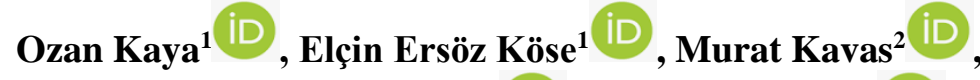 \\ Cansel Atinkaya Baytemir ${ }^{1}$ iD, İrfan Yalçınkaya ${ }^{1}$ iD
}

Sağlık Bilimleri Üniversitesi, Süreyyapaşa Göğüs Hastalıkları ve Göğüs Cerrahisi Sağlık ve Uygulama Merkezi, Göğüs Cerrahisi ${ }^{1}$ ve Göğüs Hastalıkları² Klinikleri, İstanbul

Address: Dr. İrfan Yalçınkaya, irfanyalcinkaya@gmail.com

How to cite: Kaya O, Köse EE, Kavas M, Baytemir CA, Yalçınkaya İ. A case of solitary fibrous tumor incidentally detected during COVID-19 infection and treated with video-assisted thoracoscopic surgery. J Surg Arts 2021;14(2):86-88. DOI: http://dx.doi.org/10.14717/jsurgarts-210207

Received: 25.06.2021 Accepted: 05.07.2021

\section{ABSTRACT}

Although solitary fibrous tumor is the most common benign pleural tumor, it is encountered incidentally and very rarely. A mass in the chest wall was detected in a computerized chest tomography taken due to COVID19 infection in a 36-year-old female patient. The case with solitary fibrous tumor originating from the parietal pleura was treated with video-assisted thoracoscopic surgery. During the COVID-19 epidemic, computerized tomography of the thorax, which is frequently taken for lung involvement, can reveal pathologies related to thoracic structures as well as tumors originating from the pleura. Video-assisted thoracoscopic surgery recommended for the excision of pedunculated and less than $5 \mathrm{~cm}$ lesions; We would like to emphasize that it can be safely applied in the treatment of solitary fibrous tumors that are sessile and do not exceed $5 \mathrm{~cm}$.

Keywords: COVID-19, pleura, solitary fibrous tumor, video-assisted thoracoscopic surgery.

\section{ÖZET}

Soliter fibröz tümör, en sık görülen benign plevra tümörü olmasına karşın tesadüfen ve çok nadir rastlanır. Otuzaltı yaşındaki bir kadın hastada COVID-19 enfeksiyonu nedeniyle çekilen bilgisayarlı toraks tomografisinde göğüs duvarında kitle saptandı. Parietal plevradan köken alan soliter fibröz tümörlü olgu, video-yardımlı torakoskopik cerrahi ile tedavi edildi. COVID-19 salgını sırasında akciğer tutulumu için sıklıkla çekilen bilgisayarlı toraks tomografilerinde, toraks yapılarına ait patolojilere rastlanılabildiği gibi plevra kaynaklı tümörlerle de karşılaşılmaktadır. Saplı ve $5 \mathrm{~cm}$ altı lezyonların eksizyonunda önerilen video-yardımlı torakoskopik cerrahinin; sapsız ve 5 cm'yi fazla geçmeyen soliter fibröz tümörlerin tedavisinde de güvenle uygulanabileceğini vurgulamak istiyoruz.

Anahtar kelimeler: COVID-19, plevra, soliter fibröz tümör, video-yardımlı torakoskopik cerrahi.

\section{GİRIȘ}

Visseral ve parietal plevra kaynakl1, primer veya sekonder çok çeşitli tümör ya da tümöre benzer patoloji meydana gelebilir. Bunların $\% 5$ 'i benigndir. Tesadüfen ve çok nadir rastlanılmasına karşın, soliter 
fibröz tümör en sık görülen benign plevra tümörüdür. $(1,2)$.

Klinik semptomları ağrı, öksürük ve dispnedir. Çoğunlukla visseral plevra kökenli ve saplıdır (1). Görüntülemesinde bilgisayarlı tomografi (BT) ve gerektiğinde pozitron emisyon tomografi (PET-BT) kullanılmaktadır. (3)

Kesin tanı ve tedavisi genellikle birlikte olup kitlenin büyüklüğüne göre torakotomi, video yardımlı mini torakotomi ya da video yardımlı torakoskopik cerrahi (VATS) uygulanabilmektedir. $(1,2,4-7)$

Gögüs duvarında kitle ön tanısı ile VATS uygulanan ve soliter fibröz tümör tanısı alan bir olgumuzu sunmayı amaçladık.

\section{OLGU}

Otuz altı yaşındaki kadın hasta COVID-19 enfeksiyonu nedeniyle takip edildiği göğüs hastalıkları polikliniğinden, çekilen toraks BT'sinde sol gögüs duvarında kitle tespit edilmesi üzerine kliniğimize yönlendirildi. Kliniğimize başvurduğunda kliniği tamamen düzelmiş ve akciğerlerinde enfeksiyona ait bir bulgu yoktu. BT raporunda; sol üst zonda, plevral tabanlı, 4x2 $\mathrm{cm}$ boyutlarında izlenen kitlenin PET-CT'sinde, SUDmaks: 2 olarak belirtildi ve ek tutulum odağı görülmedi. Akciğer parankimi ile ilişkisi net olmayan lezyona VATS ile yaklaşım planland. Sol arka aksiller hat 5. ve orta aksiller hat 3. interkostal aralıklardan $1 \mathrm{~cm}$ 'lik kamera portu ve $2.5 \mathrm{~cm}$ 'lik çalışma portu insizyonları ile toraksa girildi. Lezyonun posterior gögüs duvarında akciğerle ilişkisi olmadığ1 gözlendi. Subplevral kitlenin $1 \mathrm{~cm}$ anteriorundaki parietal plevra açıldı. Göğüs duvarına invazyon göstermeyen kitle, etrafındaki parietal plevra ile birlikte güvenli cerrahi sınır gözetilerek total eksize edildi. (Resim 1) Frozen benign olarak bildirildi. Patolojide; makroskopik olarak $5.5 \times 5 \times 1.5 \mathrm{~cm}$ boyutlarında, kapsüllü görünümde, sarımsı renkte, kesit yüzü solid, fibriler yapıda, parlak olan kitlesel lezyon, immünohistokimyasal inceleme sonunda benign mezenkimal tümör (ön planda soliter fibröz tümör) olarak raporland1. Ameliyat sonrası 2. gününde göğüs tüpü çekilip 3. gününde taburcu edilen hastanın 6 . ayında takipleri sorunsuz olarak devam etmektedir.
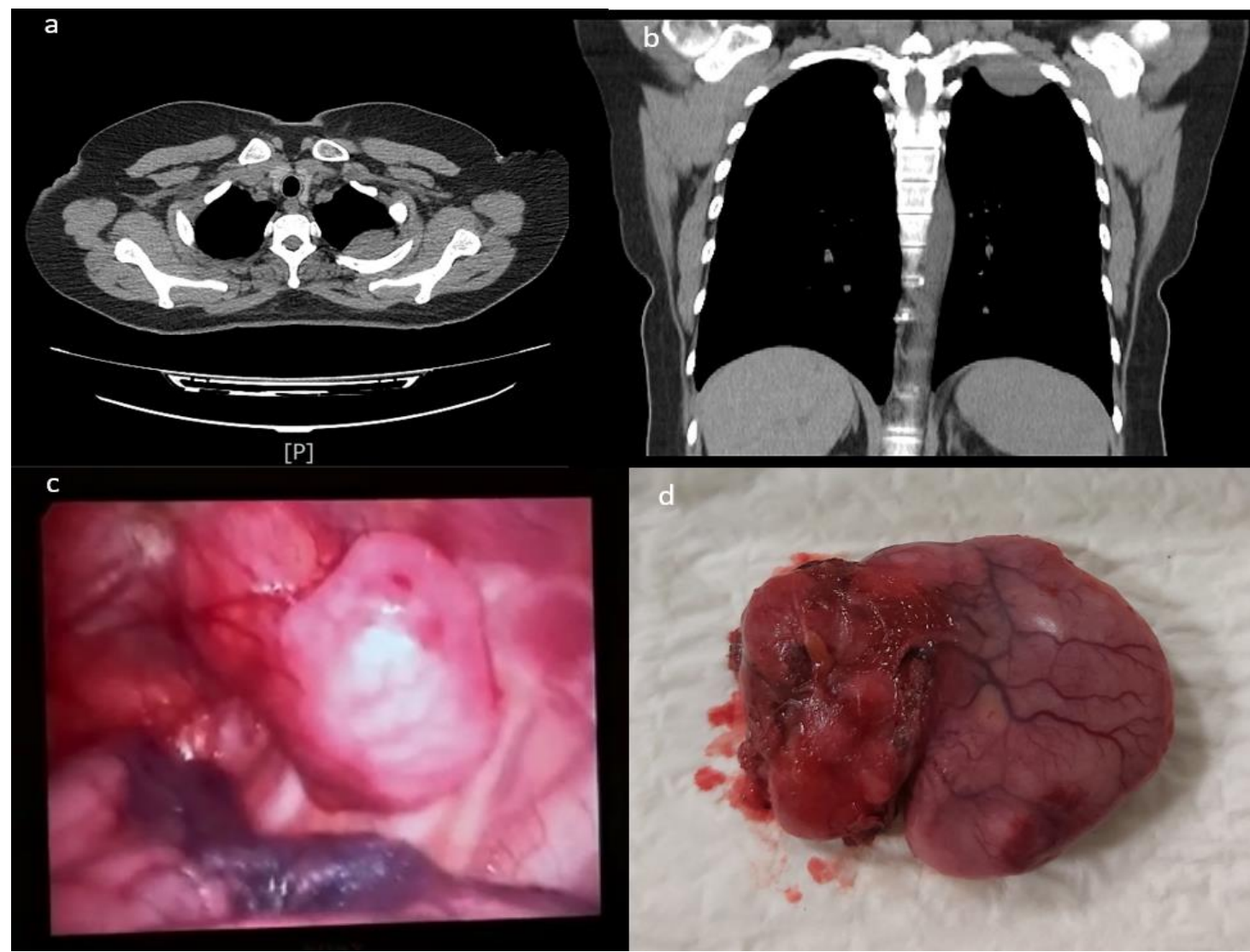

d

Resim 1: a) Lezyonun BT aksiyal kesit görünümü b) Lezyonun BT koronal kesit görünümü c) Lezyonun videotorakoskopik görünümü d) Piyesin makroskopik görünümü.

\section{TARTIŞMA}

Plevranın soliter fibröz tümörü, nadir rastlanan fibroblastik yapıda tümörler olmalarına karşın, en sık tespit edilen benign plevral tümörlerdir. Mezotel- yal tabakadan kaynaklanır. Genellikle adından da anlaşılacağ1 gibi soliterdir. Beraberinde paraneoplastik sendromlar da görülebilir. $(1,2)$ Hastamız asemptomatik ve herhangi bir paraneoplastik sendroma ilişkin bulgusu yoktu. 
Herhangi bir yaşta gelişebilirse de cinsiyet ayrımı olmaksızın en sık 6 . ve 7. dekatlarda tespit edilir. (2) Hastamız 3. dekatta olup genç hasta grubundadır. Az sayıda da olsa genç hastalarda da saptanabilir. (4)

Çoğunlukla klinik bulgu vermediklerinden uzun süre tanısız kalarak büyük boyutlara ulaşabilirler. Tanısal süreçte ilk basamak çoğunlukla akciğer grafisinde ve toraks BT'de lezyonun tesadüfen saptanmasıdır. Olgumuzda olduğu gibi COVID-19 salgını sırasında akciğer tutulumunu ortaya çıkarmak amacıyla çekilen akciğer grafilerde ve özellikle toraks BT'lerde, başta soliter pulmoner nodüller, erken evre akciğer kanseri, plevra ve mediastene ait lezyonlara ait patolojiler olmak üzere tesadüfen tespit edilebilmektedir.

Düz grafide yerleşim yerinden bağımsız olarak, düzgün sınırlı homojen tek odaklı opasite olarak izlenirler. Yine tümörün tanısal görüntülenmesinde öncelikli olarak BT önerilirken, ilerleyen olanaklarla beraber PET-CT kullanımı artmıştır. FDG-18 tutulumu ile malignite insidasının doğru orantılı olduğu düşünülmektedir. Toraks BT'de çoğunlukla düzgün sınırlı, nadiren lobüle olsa da büyük oranda çevre dokuya infiltrasyon göstermeyen ve visseral plevra ile sınırlı homojen içerikli soliter lezyonlar olarak izlenirler. (3)

Soliter fibröz tümörler, literatürde çoğunlukla saplı yapıda ve \%80'i visseral plevra kaynaklı büyük çaplara ulaşabilen kitleler şeklinde görülmesine karşın, geriye kalanlar ise diyafragmatik veya mediastinal parietal plevradan çıkar ve bunlar daha çok pedinkülsüzdür. $\% 3.5$ oranında intraparankimal yerleşim olabilir. (1-3,5) Olgumuzda ise lezyon sapsiz ve parietal plevra kaynaklı idi.

Tanı preoperatif dönemde biyopsi yapılsa bile konulamayabilir, bu nedenle tanı ve tedavi genellikle birlikte gerçekleştirilir. Olguların küratif tedavisinde komplet cerrahi rezeksiyon esastır.

Pedinküllü olguların tedavisinde VATS ile girişim tercih edilmelidir $(4,5,7)$. Komplet rezeksiyon amacıyla tümörün çevresindeki sağlam dokudan da bir cm sınır kalacak şekilde çıkarılması önerilmektedir. VATS ile çıkarılamayacak kadar büyük olan tümörler, video yardımlı mini torakotomi ya da torakotomi ile çıkarılmalıdır. Pariyetal plevradan kaynaklanan tümörlerde parsiyel pariyetal plevrektomi de eklenmelidir. $(1,2,6)$ Olgumuzda tümör parietal plevradan kaynaklanmış olup göğüs duvarına invaze değildi ve künt diseksiyonla rahatlıkla ayrılabildi. Tümör çevresindeki bir $\mathrm{cm}$ parietal plevra ile birlikte total olarak eksize edildi.

Nüks veya malign transformasyon şüphesi varlığında göğüs duvarı rezeksiyonundan kaçınılmamalıdır. Pedinkülsüz olan $5 \mathrm{~cm}$ 'den büyük lezyonlarda torakotomi ile rezeksiyon önerilmektedir. Bazen akciğer parankim tutulumu nedeniyle akciğer rezeksiyonu gerekebileceği akılda bulundurulmalıdır. Nüks tümörler birden çok yerde gelişebilir ve malign transformasyon gösterebilir. $(1,2,6)$
Histopatolojik olarak benign olduğu tespit edilen tümörlerde bile olgunun takibi gereklidir. Nüks veya malign transformasyon ihtimalinden dolayı tümör, minimum bir cm negatif cerrahi sınır sağlanarak rezeke edilmelidir. $(2,6)$ Yavaş büyüme eğilimine rağmen asemptomatik olgularda, tanının gecikmesi ile tümörün büyük boyutlara ulaşıp büyük vasküler yapılardan beslenebileceği unutulmamalıdır.

Küçük ve saplı tümörlerde VATS önerilirken, $5 \mathrm{~cm}$ 'den büyük ve sapsız tümörlerde torakotomi ön plandadır. $(1,2)$ Olgumuzdaki tümör sapsız ve 5.5 $\mathrm{cm}$ boyutunda olmasına karşın VATS ile rahatlıkla çıkarılabildi.

\section{Sonuç}

COVID-19 salgını sirasında akciğer tutulumu için sıklıkla çekilen toraks BT'lerde toraks yapılarına ait patolojilere rastlanılabildiği gibi, plevra kaynaklı tümörlerle de karşılaşılmaktadır. Saplı ve 5 cm altı lezyonların eksizyonunda önerilen VATS'ın; sapsız ve $5 \mathrm{~cm}$ 'yi fazla geçmeyen soliter fibröz tümörlerin tedavisinde de güvenle uygulanabileceğini vurgulamak istiyoruz.

\section{KAYNAKLAR}

1. Doğruyol T, Atinkaya C, Yalçınkaya İ. Plevranın benign tümörleri. Eren TŞ, editör. Torasik Cerrahi. 1. Baskı. İstanbul: İstanbul Tıp Kitabevleri; 2019; 905-911.

2. Yalçınkaya S. Plevranın primer soliter tümörleri. Şahin E, editör. Her Yönüyle Plevra ve Hastalıkları. Sivas: Cumhuriyet Üniversitesi Yayınları, 2018; 255-260.

3. Salahudeen HM, Hoey ET, Robertson RJ, Darby MJ. CT appearances of pleural tumours. Clin Radiol 2009; 64(9):918-930.

4. Hayama M, Maeda H. [Solitary fibrous tumor of the parietal pleura resected by video-assisted thoracic surgery; report of a case]. Kyobu Geka 2010; 63(6):492-495.

5. Mazzella A, Izzo A, Amore D, Cennamo A, Cerqua FS, Perrotta F. Single port VATS resection of a sessile solitary fibrous tumour of the visceral pleura. A case report. Ann Ital Chir. 2015 Sep 24;86(ePub):S2239253X15024457. PMID: 26394843.

6. Misırlığlu AK, Alpay L, Kanbur S, Öztaş S, K1ral H, Doğruyol T, Baysungur V, Yalçınkaya İ. Pleural solitary fibrous tumors: an analysis of 11 cases. Turk Gogus Kalp Dama 2014; 22(2):376381.

7. Ergene G, Halezeroğlu HS, Okur E, Demirhas MP, Tokat F. Mediastinal hastalıklarda tek insizyon video yardımlı torakoskopik cerrahi: Tek merkezli deneyim. SDÜ Tıp Fak Derg 2019; 26(3):328-334. 